\title{
Key Factors for Shortening Response Time in the Strategic Issues Diagnosis Process
}

\author{
Jodi A. Potter \\ Marcel Minutolo \\ Robert Morris University \\ John Lipinski \\ West Virginia Wesleyan College
}

\begin{abstract}
Strategic Issue Diagnosis research focused on the complexity of decision making in a turbulent environment; the cognitive processes associated with interpretation; and, political issues embedded in strategic decision making. However, speed has been ignored. Information gathering and sense making of data through competitive intelligence processes affects the speed associated with interpretation, analysis, and decision making. Through a questionnaire administered in the Pittsburgh region, we identified within organizational factors that assist in counteracting the recursiveness and redundancy inherent in the process hastening strategic decision making. Analysis based on Partial Least Squares regression techniques with bootstrapping enabled generalization of previous research includes the role of speed.
\end{abstract}

\section{Introduction}

Proactive management techniques, nimble processes, and systems that allow an organization to be responsive and build rapid decision making capabilities are an important determinant of success in a turbulent environment (Brown \& Eisenhardt, 1998; Eisenhardt, 1989; Meyers, Goes, \& Brooks, 1993). Over the past few decades there has been significant attention directed at the strategies a firm uses to obtain competitive advantage in a turbulent environment or an environment characterized by continuous change, uncertainty, or complexity. Strategic Issue Management (SIM) systems involve 'real-time' or 'online' processes for the development of capabilities to effectively handle discontinuities or crises that occur in turbulent environments (Ansoff, 1980, 1991; Pitt, 2005).

Strategic Issue Dagnosis (SID) is an inherent part of a SIM system. The focus of SID is on how data and stimuli get interpreted and understood (Holt, 2006) with an emphasis on extensive interaction among decision makers. SID recognizes that strategic issues arise from disorderedly and conflicting data and require some form of interpretive schema to transform them into usable information. Developing a response is time consuming, and in many cases the firm's chosen response can be ineffective due to a lack of productive analysis related to the specific issue in question (Heath, 2002).

D'aveni (1995) suggests that success in a turbulent environment is often tied to speed 
of response. The speed with which the firm is able to interpret and understand the scope and impact of each unique issue through a diagnosis process is a critical component of effective SID and crucial to its competitive advantage. Given how important reaction time to environmental changes is to organizational performance, it is necessary to understand the within organizational factors that increase the speed of issues diagnosis.

The remainder of the paper is structured as follows. Following the introduction, we introduce strategic issues and strategic issues diagnosis; next, the role that speed plays in strategic issues diagnosis. We then develop the hypothesis. After the development of the hypothesis, we introduce the sample followed by the data collection in the methodology section and a discussion of the variables. We then provide the results of our hypothesis test using partial least squares regression with the bootstrapping approach. Finally, we discuss the results, managerial implication, and shortcomings of the study, and offer suggestions for future research.

\section{Strategic Issues}

According to Ansoff (1980) and King (1982), a strategic issue is an event that has a significant performance impact on the firm or one that has strategy consequences. As such, the domain subsumed by an "issue", especially in its early stages, is likely to be broad, diffuse, and ill-specified (Dutton, Fahey, \& Narayanan, 1983). Issues can arise from a number of sources, both internal and external to the firm, but rarely does a strategic issue arrive in a wholly recognizable form. Information flows into the organization through many different channels; it arrives as a series of weak signals from a variety of sources; Pitt (2005) provides a good model that illustrates this point (see especially Figure 1, p. 310). The firm's scanning activities are the main tool used to transfer these signals to key decision makers (Heil 1991; Smith \& Grimm 1991).

A Strategic Issue Management (SIM) system is designed to continually capture signals from the environment and facilitate a real-time process to incorporate the information being gathered into strategic decision making. The system is designed for use in turbulent environments. According to Ansoff (1980) a turbulent environment is characterized by a high degree of change and unpredictability. Traditional strategic planning systems often fail to assure timely response in states of high turbulence. Systems failure occurs due to the speed of change and low expectancy (Pitt, 2005) which creates discontinuities that impact the organization planning processes to determine an effective response. It is in these environments where the effectiveness of real-time or on-line systems, like SIM systems for strategic response are required.

\section{$\underline{\text { Strategic Issues Diagnosis }}$}

Strategic Issue Diagnosis (SID) is a fluid, emergent, and dynamic process that occurs within a SIM system. It involves dealing with complex, novel, and open-ended decisions that contain interdependent elements (Mintzberg, Raisinghani \& Theoret, 1976). The focus of SID is on how data and stimuli get interpreted and understood. The emphasis 
is upon extensive interaction among decision makers. Dutton, Fahey and Narayanan (1983) supplied a framework for discussing SID (see Figure Figure 1).

\section{Figure 1. Dutton, Fahey, and Narayanan (1983) SID Model}

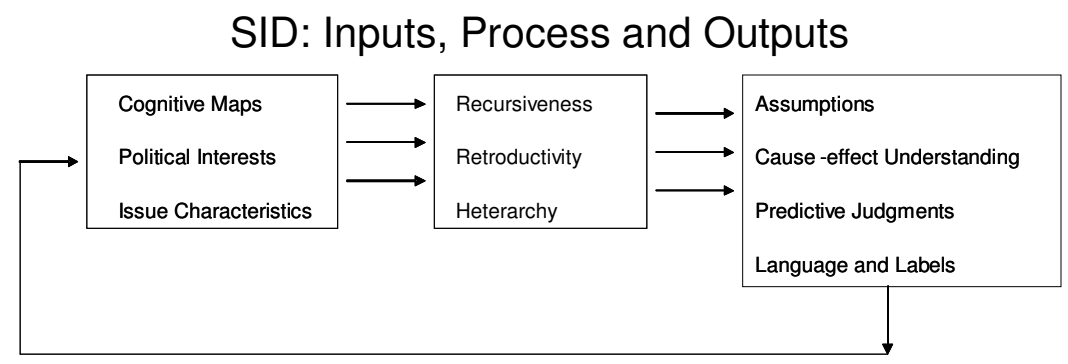

In their model, the authors recognize that strategic issues arise from disorderedly and conflicting data that require some form of interpretive scheme to transform this data into usable information. Their framework is comprised of inputs, a process, and outputs of SID. They identified cognitive maps and the political processes of decision makers, along with issue-specific characteristics as important inputs in the altering of data to useful information by individual decision makers. Cognitive maps represent the beliefs held by an individual, and influence the manner in which actors assess and organize issues. Political interests arise due to the importance associated with strategic issues within the organization, resulting in the development of self-interested behavior in the diagnosis of issues (Pitt, 2005). Finally, issue characteristics influence the diagnosis process since every issue is unique requiring its own resolution process, limiting the firm's ability to use standard templates or familiar routines.

Three process characteristics were also identified by the Dutton et al. (1983): recursiveness, retroductivity, and heterarchy. Recursiveness is illustrated by the tendency for the same issue to be redefined several times throughout the decision making sequence. Revisions reflect the fluidity of participants and available data during the SID process. Data interpretation is not systematic or sequential, new and significant information arrives during all stages of the data evaluation process, causing interpretation and search to be interactive. Retroductivity revolves around issue comprehension and assumes the interaction of both deductive and inductive modes of thinking are required for the assessment of strategic issues. Managers rely upon past experience and learning to resolve complex issues. They are required to exercise judgment due to a lack of comprehensive data for decision making. Since every decision maker pulls from a diverse and unique set of experiences and learning, multiple decision makers will reduce bias associated with a unilateral approach and provide a more balanced and comprehensive assessment of the issue. In their discussion on heterarchy, Dutton et al. (1983) recognize that strategic issues are rarely diagnosed by a single individual; a number of individuals from various areas within the organization assist in the process. This causes the political interests of individuals within the organization to be activated and they attempt to use their influence to skew the 
diagnosis outputs in their preferred direction, thus impacting the organization's ability to achieve consensus and increasing the time required to diagnose the issue.

In the output stage, the diagnosis process generates a set of potentially fluid assumptions required to address the issue. However, there exists a great deal of variance with respect to individual judgments surrounding potential courses of action, different interpretations regarding language and labels applied to the issue, and the understanding of the significance of the issue to the organization's future success. Variation in individual perceptions results in differences in actor's level of urgency. The outputs serve to impact the organization beyond the domain of a single strategic issue.

All of the above descriptions of the stages of issue diagnosis are valid and important concepts associated with a successful SIM system. Previous research has captured the complexity and comprehensive impact associated with strategic issues and the related types of decision making characteristics. What is not accounted for are characteristics and/or processes designed to promote more rapid dissemination of information to areas within the organization that require it and thus increase the speed associated with the diagnosis of strategic issues.

\section{The Importance of Speed}

Rapid decision making capabilities are of interest to decision makers in organizations that operate in turbulent environments where environmental change is frequently occurring and response to this change is a necessary component of maintaining a competitive market position or gaining an improved one (Eisenhardt, 1989; Heinriches \& Lim, 2008; Smith \& Grimm, 1991). Understanding how to improve the organization's speed of response is often critical, as response speed or having the flexibility to ensure appropriate timing of a response is a crucial recourse for the organization or a vital output to be exploited (Gulick, 1987). In order to effectively compete in today's fast paced global environments, speed is increasingly becoming a critical capability.

Much of the past literature on SIMs and SIDs has not investigated the importance of speed. Instead efforts have focused on the various components of the management and diagnosis processes (Dutton, 1993; Dutton et al., 1983; Dutton, Walton, \& Abrahamson, 1989) and on the issue management performance relationship (Heugens, 2002). Others have focused their efforts on combining elements of traditional strategic planning processes with the principles of issue management (Camillus \& Datta, 1991) and topologies of SIM systems based on types of issues or the scope of activities the firm uses in its response have been developed (Dutton \& Ottensmeyer, 1987). More recently a resurgence of interest in the use of SIM systems has arisen as it relates to the literature on future studies (Schwarz, 2005) and the role of the market manager (Heinrichs \& Lim, 2008).

We suggest that increasing the speed of issue diagnosis, will in turn, increase the organization's speed of response. In order for SID to be an effective tool, the intrinsically slow characteristics of Dutton, Fahey and Narayanan's SID process need to be counteracted. 
The focus of this paper is on the importance of speed in SID and on understanding what actions an organization can take to increase diagnosis speed. We have focused on the area of competitive response as it relates to the use of competitive intelligence $(\mathrm{Cl})$ to build a set of testable hypotheses seeking to understand what internal actions can speed up the intrinsically slow characteristics of the SID process. CI routines provide firms with unique capabilities regarding the gathering of information that is used to identify issues or opportunities. Competitive response is also concerned with timing. Scholars have argued that the timing of a response is crucial to the competitive advantage of both the acting and responding firm. The acting firm can earn abnormal positive returns due to a monopolistic position it can hold prior to a rival's response (Lieberman \& Montgomery, 1988).

Our results suggest that the models and processes an organization utilizes to store and distribute its data is related to how rapid its response will be to environmental changes. The level of executive sponsorship of its competitive intelligence group is also a significant factor associated with speed of response. Finally the degree of formality as it relates to roles and staff functions within its $\mathrm{Cl}$ group is also related to increasing SID speed.

\section{Hypotheses Development}

In a competitive response situation, this first step of intelligence gathering can be more specifically defined as analysis of the current situation or retrieving and organizing the information regarding a rival's move. This typically requires data gathering from both external and internal sources in order to ensure that a complete understanding of the rival's move and its impact to the organization are clearly ascertained. The likelihood is that more information rather than less will be used for decision making. Obviously the more information there is, the more time consuming and difficult the process of sense making will be. This is similar with SID processes where the volume of information can influence both the quality and speed of issue diagnosis. Within the SID process, gathered information is transformed through the expertise of the process participants into relevant information and processing of this information is an integral part of SIM and SID. An important component of this process is ensuring that the information used is easily retrieved by the decision makers. Ensuring the relevance and irretrievability of information can involve changes in organizational structure to build better communication channels across organization boundaries and systems that support the storage, manipulation, and availability of information.

Interpretation is less effective when the quantity of information exceeds the organization's ability to process it adequately (Huber, 1991). Simon (1973) suggests that firms operating in information rich environments should seek to minimize the distribution of information across business units. As recognized by Huber (1991) reduced information sharing across the organization can curtail some types of organizational learning, a fundamental component of SID. The solution appears to be one that reduces the potential for overload without reducing the relevance of the 
information, and allows for easy dissemination throughout the organization on an asneeded basis. A process to filter the information with the intent of organizing it in a manner that reduces its ambiguity and complexity is necessary, as well as a process for storing and retrieving the information when it is required.

What is readily available or already known about a strategic issue should facilitate a reduction in the amount of inherent uncertainty management faces and thus reduce the time required for a strategic decision. Since strategic issues rarely arrive in a single recognizable form, a database would provide the benefit of storing, retrieving, and combining environmental events, signals, and market occurrences. A well-maintained and up to date information database would facilitate the organization's ability to recognize strategic issues since it would store historical data and allow for the manipulation of both newly retrieved and historical data into coherent intelligence. In addition, the building blocks for the development of a strategic issue could exist and be located in the database, and therefore much of what was required to be processed by decision makers might already be in existence, able to be easily accessed by key decision makers, and perhaps already ingested and recognized as facts by management.

The successful use of market intelligence often requires information technology in the form of competitive intelligence tools that aid managers in filtering and sifting through volumes of available information (Chen, 1995). Thus achieving competitive advantage lies in the firm's ability to effectively use their intelligence not solely from access to it (Maltz \& Kohli, 1996). Cl tools and models are designed to provide managers with rapid access to expanding amounts of information stores (Benjamin \& Levinson, 1993) and in this manner, aid in the speed of strategic decision making.

Hypothesis 1: The greater the use of $\mathrm{Cl}$ models designed to improve storage and distribution of information and facts, the more rapid will be decision making associated with SID.

An important activity associated with $\mathrm{Cl}$ decision making is environmental scanning and involves both the accumulation and processing of information (March \& Simon, 1958; Simon, 1960). Scanning is the first step in organizations adapting to their environment (Child, 1972; Daft \& Weick, 1984) and is an important process associated with the gathering of information and can increase performance in turbulent environments. In uncertain environments, chief executives of high performing companies reported scanning more broadly and more frequently. They directed their scanning efforts to sectors where the greatest amount of uncertainty existed and relied heavily on scanning from both internal and external sources. Thomas (1980) identified different scanning intensities; irregular, regular, and continuous. The method chosen was determined by the content required, the time available, and the space (size) of the end user. Content consists of scope, range, and futurity. Organizations with information needs characterized by a broader continuum, global versus localized perspectives, and a high degree of interest in long-term future events increased scanning frequency. On the opposite end of the scale, organizations with information needs characterized by a 
narrow continuum, localized perspectives, and low interest in predicting future events were irregular and less frequent in their scanning activities. Environments that are unpredictable and have rapid continuous change would require continuous scanning since irregular or regular scanning activities would not provide sufficient information regarding occurrences or events. Therefore SID, being a process that is designed to operate in a turbulent environment, would benefit from frequent environmental scanning.

Hypothesis 2: The frequency of an organization's environmental scanning processes will have a direct effect on the speed of SID.

Likewise, having a single group of knowledgeable intelligence experts whose function is to accumulate and filter the high volume of information coming from boundary spanners would also increase speed within the SID process. Combining events into strategic issues is a learning process. It involves both tacit and explicit knowledge. It begins at the individual level and then is transferred to the sector of the organization that requires it. Intelligence experts would rely upon their own cognitive maps and mental models to recognize key triggers for the combining of events into strategic issues. At the same time, they may also rely upon an extensive network of contacts from both within and outside the firm to deepen and broaden the perspective they gain from the information gathered. The experience necessary to conduct this type of assessment along with the time and effort required to build a network of valuable contacts is best garnered through an intelligence group that is dedicated to their function. Part-time intelligence professionals or those with conflicting responsibilities would reduce the effectiveness of this group's ability.

The role of this group would be to maintain the information database and provide primary support to key decision makers when a strategic issue arises. This would increase the organization's SID speed by reducing the recursiveness and retroductivity of the process. Key resources would be immediately available, and the intelligence experts could provide their expertise and experience in addressing a strategic issue, thus reducing the potential for the key decision makers to continually reassess the meaning of a strategic issue and thus extend the analysis beyond what is necessary. Galbraith (1973) emphasized structural characteristics of high participation and interaction and low levels of formalization to facilitate a high level of information processing. These individual would stimulate ongoing discussion and interaction regarding environmental events. They could provide timely and relevant information to support decision making, but do so in an efficient and nimble manner; interjecting themselves in and out of the process on an as-needed basis. Based on their ability to reduce recursiveness and retroductivity in the SID process and their focus on instilling ongoing interaction and nimble support to decision makers, it seems logical that the following will hold true:

Hypothesis 3: The presence of a formal intelligence group, dedicated to their function acting as a point of contact for key decision makers, will speed SID. 
Intelligence personnel would need to be recognized as credible and influential at the organizational decision making level since the only relevant learning that occurs in an organization is by those who have the power to act upon it (De Gues, 1988). The reputation they hold would be an important criterion for their ability to influence decision makers and reduce the amount of retroductivity inherent in the SID process.

Sponsorship by top management is also a critical building block of their reputation or influence. There is a significant amount of research that links the role and characteristics of top management to outcomes inherent within strategic decision making (Lewin \& Stephens, 1994; Meyers and Goes, 1988; Rajogopalan, Rasheed, \& Datta, 1993;). Tee, Bowen, Doyle, \& Rohde (2007) found management's commitment to data quality and the presence of data quality champions strongly influences data quality. In the information systems (IS) field, researchers have found that senior champions or top management interest is critical to the success of IS decision making (Johnson \& Carrico, 1988; Reich \& Benbasi, 1990). Therefore having top management support may be a critical component of developing a reputation that can influence decision makers and thus reduce retroductivity in the SID process.

Hypothesis 4: Sponsorship by top management will positively related to the speed of decision making associated with the process of SID.

\section{Method \\ Population / Sample}

Following Julian \& Ofori-Dankwa (2008), we used a multi-industry sample constrained by geography (Pittsburgh, Pennsylvania). The Pittsburgh geography represents a good test sample for the model given the city's economic redevelopment efforts, stable growth rate, and relatively central distribution of major firms. We feel comfortable that the current economic climate along with this region's downturn during the 1980s and 1990 s and its movement from the steel industry to high technology constitutes an environment characterized by unexpected change and unpredictability. We targeted mid- to large-firms as defined by sales and number or employees. According to sales, the single greatest range of participant firms is between $\$ 50$ and $\$ 100$ million per annum; by number of employees, the largest category is represented by firms with between 500 and 900 employees.

We randomly selected 200 firms from a variety of industries. The industries represented, with Standard Industrial Codes in parenthesis, include: agricultural services (07); building construction (15); leather and leather products (31); transportation (41); wholesale trade (51); building materials (52); business services (73); and, other services (89).

Figure 2 illustrates the distribution of the sample by Standard Industrial Classification (SIC) code. 
Figure 2. Frequency Distribution of Sample by Standard Industrial Classification (SIC) Code

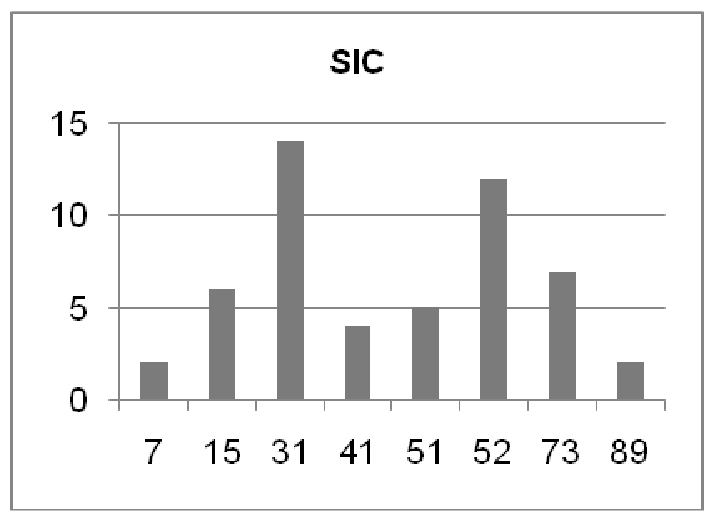

The CEO/President was the target respondent for the study. The $\mathrm{Cl}$ unit of the firm exists to provide actionable intelligence to the decision maker. Further, the decision maker ought to be well versed in the interpretation of strategic issues (Brown and Lusch, 1992; 2008) and possess more strategic issues related information than others throughout the organization (Branzei, Ursacki-Bryant, Vertinsky, \& Zhang, 2004). Therefore, the CEO/President appears to be the most appropriate respondent.

\section{Data Collection}

Following Julian \& Ofori-Dankwa (2008) and Dillman (2000), we sent an initial notification letter to the contacts in the sample as well as two rounds of surveys. A short introduction at the start of the survey reinforced the impact that the question has on speed in decision making and explicitly requested that the CEO provide answers with respect to the views of the firm's 'top management.' Given these questioning conditions, the CEO represented an 'informant' (Julian \& Ofori-Dankwa, 2008) since the information provided is relative to a condition that the individual has privileged access to; this is opposed to the CEO as a respondent (i.e. an individual providing personal opinion). Within two weeks of the distribution of the initial survey, we followed up with phone calls to stimulate response.

We received 52 usable responses total for a response rate of approximately 26 percent, which compares favorably with the 10 to 12 percent response rate typical for executives in large U.S. firms (Hambrick, Geletkanycz, \& Fredrickson, 1993). The distribution of the firm size and age of $\mathrm{Cl}$ unit was $\$ 50$ and $\$ 100$ million and between 3 to 5 years old respectively. We tested for response bias in the sample by correlating survey response time with each of the variables in our study, a commonly used practice (Julian \& OforiDankwa, 2008; Hawes and Crittenden, 1984). No significant correlations at the 0.05 level were found between response time and the variables; therefore, the test for response bias is rejected.

\section{Measures}


Given the brevity of this paper and the venue that it is presented in, we only present one portion of the total model; and, therefore, only those measures relevant to that part of the model designed to capture the relationship between the formal structure of the $\mathrm{Cl}$ group in the firm and the speed of decision making are presented. The full model with loadings and $R^{2}$ values is presented in Figure 3 . The latent variables highlighted by the box in Figure 3 are the variables discussed here. These variables capture the relationships established in the hypotheses. The other clusters and nodes in the model are presented elsewhere.

\section{Control variables}

Various factors explain the need for $\mathrm{Cl}$ activities in an organization and speed in decision making including the firm's industry, its financial condition, and the age of the $\mathrm{Cl}$ function. Industry is coded as the two-digit Standard Industry Classification (SIC) code. Year Range is a measure of the age of the firm that accounts for the overall 'maturity' of the organization and therefore the routinization of processes. Age of Cl (Age_Cl) accounts for the overall age of the $\mathrm{Cl}$ unit in the organization (i.e. how long the $\mathrm{Cl}$ function has been formalized) and therefore accounts for the maturity of the $\mathrm{Cl}$ function. It is important to control for the age of the $\mathrm{Cl}$ function because we would expect that CEOs in organizations with younger $\mathrm{Cl}$ units may not fully utilize the production capabilities that the unit is able to produce. Number of Employees (Num_Emp) and Dollar Range (SIs) controls for the size of the organization since larger organization may be able to devote more resources toward $\mathrm{Cl}$ than smaller firms.

Independent (latent factors) variables

For the purposes of this study, we are interested in the latent variables that are attributable to the improved speed of decision making and we sought to address this through structural identification of required firm actions. In order to ensure that we accurately captured each of the latent variables, we asked the respondents to identify those components necessary to the structural development of the $\mathrm{Cl}$ operations as it relates to their own organization. For the sic latent variables illustrated in this particular study, there were a total of 49 indicators that loaded on the variables.

Four latent structures comprised two clusters in the model. The latent variables

Distribution and Storage load on the cluster IT (information technology). The IT systems within an organization form the basis through which the $\mathrm{Cl}$ function communicates it messages, pushes and pulls intelligence, and maintains the repositories of its efforts. Given the nature of the IT system, we chose to divide the IT structure into its two components; the passive function of storage, and the active function of distribution.

The Intelligence Group (IG) cluster is divided into the latent variables Presence and Formal. The latent variable Presence captures the formal presence or absence of particular 'types' of individuals within the intelligence group. In particular, the Presence variable captures the impact that full-time, part-time, volunteer, external (i.e. consultants), and various other management have on the speed of decision making. On the other hand, the Formal variable accounts for the formal role that various functions 
play in the IG. In particular, Formal accounts for the degree to which defined frameworks and processes are used within the $\mathrm{Cl}$ function.

Frequency is measured by the degree to which various members within the organization use the $\mathrm{Cl}$ group and its products and how often information gathered by boundary spanners is transferred to the IG. One might expect that top management, being key decision makers in the organization, would have more frequent use of the products produced by the $\mathrm{Cl}$ group and thereby this would increase decision making speed. In order to test this assumption, we surveyed the frequency of use by a variety of functional areas within the organization, such as the board of directors, marketing, research and development, as well as other groups. In turn, we also gathered information on which functional areas had the highest levels of frequency associated with the provision of information to the IG.

Initiated_by captures the belief that the higher the level of sponsorship of the $\mathrm{Cl}$ function, the greater the use of, the more support to, and the greater the level of resources available to the $\mathrm{Cl}$ function. It is expected that the higher in the organizational hierarchy that the initial sponsor of the $\mathrm{Cl}$ program resides, the greater the use throughout the organization $\mathrm{Cl}$ products will have and the more effective will be its outputs as they relate to decision making speed.

\section{Dependent variable}

The dependent variable, improved speed of decision making (spd), cannot be observed directly and therefore must by measured through perceptions by decision makers.

Although we specifically asked the respondents to answer each of the survey questions with respect to the influence on speed in decision making, we further asked the respondents to answer a perceptual question that required the respondent to report on his or her feelings of the impact on speed. More than half (60 percent) of the respondents answered that they believe the presence of a formal $\mathrm{Cl}$ unit increased their ability to make decisions more rapidly.

\section{Analysis}

We chose path analysis to test the hypotheses due to the method's ability to decompose effects into both direct and indirect components (Kenny, 1979; Ginsberg \& Venkatraman, 1992). In particular, we identified the relative magnitude of both the direct and indirect effects through inputs, processes, and outputs in SID on the speed of decision making and the reputation of the $\mathrm{Cl}$ unit in an organization (see Figure 3).

Due to the small sample size (52) relative to the number of survey questions (180), we carried out the analysis using Partial Least Squares (PLS) regression with bootstrapping techniques in order to enable some generalization of the results. PLS as an appropriate methodology given small sample sizes have been demonstrated in other studies (Gudergan, Ringle, Wende, \& Will, 2008; Mangin, Valenciano \& Koplyay, 2009; Sosik, Kahai \& Piovoso, 2009;). We utilized SmartPLS software, available athttp://www.smartpls.de, to model the variables under study. 
The PLS methodology is based on the regression of latent variables and does not have the same requisites for sample size, the normality of data or for the scales' validation as does optimization methods such as Structural Equation Modeling. PLS is oriented to model predictability (Chin, 1998; Chin \& Frye, 2003). The estimates' stability is measured by the Student T-statistic determined by a bootstrapping made over 500 random samples (Mangin, Valenciano, \& Koplayay, 2009; Sosik et al., 2009).

In Figure 3, the direction of the arrow, where it points from the cluster node to the latent variable, should be interpreted as a reflexive indicator and the number on the line as a path loading. Where the arrow points toward the node (toward the center of the diagram) and away from the indicator or latent variable, it is interpreted as a formative indicator and the value as a regression weight. The numbers provided within the circles are the $R^{2}$ values and may be read like traditional interpretation of the value.

\section{Results}

\section{$\underline{\text { Convergent Validity and Reliability Measures }}$}

The individual reliability for each item is given by loadings or correlations between the indicator and the latent variable. The convergent validity of each indicator is acceptable 


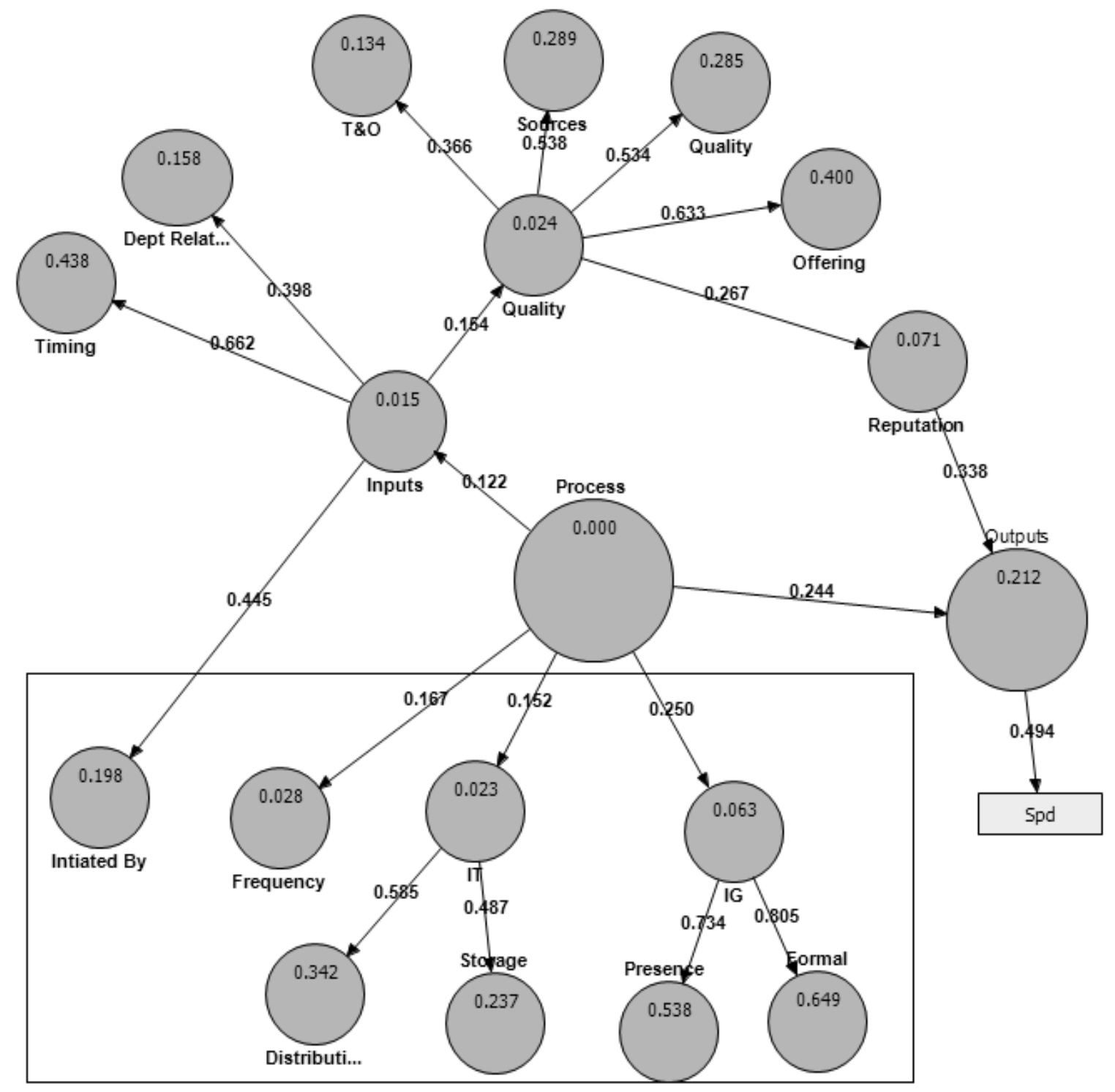

for a loading $>0.50$ (Falk \& Miller 1992). Only the reflective indicators (not shown on model) that met this threshold were kept in the model; all others were 'pruned'. Hence, all indicators kept in the model achieved convergent validity.

The bootstrapping method was used to test the significance of the path coefficients. Significance is achieved if the Student T-measure is greater than $|1.96|(\operatorname{Pr}(1$-alpha) $\leq$ to 0.05 ) (see Table 1). The value of the measurement is provided under the 'value' header and is interpreted based on the type of value that it is with respect to the model and may be found under the 'Indicator Type' header. Where the indicator type is 'pruned' the variable was removed from the model due to lack of significance. We removed any indicator from the model that had a bootstrap value below 1.0 since there is no instance where the bootstrap would return a significant bootstrap value of 1.96. 
Where the 'Indicator Type' is a reflective indicator, then the 'Value' is the measure of the factor loadings emerging from the latent variable (Sosik et al., 2009).

Previous research has suggested that anything that has an $R^{2}$ below 10 percent $(0.10)$ may be excluded from the model. However, we included nodes with below 10 percent values since we are testing a previously untested model (Dutton et al., 1983) and as such there is value in validating our survey before any further research efforts are pursued. In addition, we attempted to extract those indicators that truly represent the latent variables that we purported to test for. Therefore some of the below 10 percent measures that we realized may be due to questioning more than model specification. However, as research testing in this domain moves forward, researchers may find that the original model specified by Dutton et al. (1983) may not reflect the true nature of the 'world' and those latent variables with less than 10 percent may be removed.

Table 1. Summary of Variable Findings

$\begin{array}{lllll}\text { Latent Variable } & \text { Indicator Type } & \text { Value } & \mathrm{R}^{2} & \text { Bootstrap } \\ \text { Ind } & \text { Reflective } & 18.939 & \mathrm{NA} & 2.759 \\ \text { Siz_DIr } & \text { Pruned } & - & & - \\ \text { Age_Yr } & \text { Pruned } & - & & - \\ \text { Age_Est } & \text { Pruned } & - & & - \\ \text { Siz_Emp } & \text { Pruned } & - & & - \\ \text { INITIATED BY } & \text { Factor } & 0.445 & 0.198 & 3.336 \\ \text { FREQUENCY } & \text { Factor } & 0.152 & 0.023 & 1.108 \\ \text { IG } & \text { Factor } & 0.25 & 0.063 & 1.99 \\ \text { PRESENCE } & \text { Factor } & 0.734 & 0.538 & 10.286 \\ \text { FORMAL } & \text { Factor } & 0.805 & 0.649 & 14.384 \\ \text { IT } & \text { Factor } & 0.152 & 0.023 & 1.937 \\ \text { STORAGE } & \text { Factor } & 0.487 & 0.237 & 5.338 \\ \text { DISTRIBUTION } & \text { Factor } & 0.585 & 0.342 & 9.152 \\ \text { SPEED } & \text { Reflective } & \mathbf{0 . 4 9 4} & & \mathbf{4 3 . 7 1 8}\end{array}$

Another reason to accept values below the 10 percent threshold is many of the nodes below a 10 percent value have latent variables significantly higher. For instance, where the $\mathrm{R}^{2}$ for Quality node is 0.024 , the R-square for its latent variables are above the threshold (e.g. T\&O is 0.134; Sources is 0.289; and Quality is 0.285 ). Furthermore, the indicators that determine the weights of the latent variables included in the final model are all significant and tell very interesting stories that are managerially relevant.

\section{Discussion}

\section{Hypothesis Findings}

This model is stable and positively responds to all accepted criteria of composite reliability, convergent and discriminant validity. The regression coefficients are based on 
a bootstrapping of 500 samples and not on the sample estimators; this allows the generalization of the results and the computation of the Student $T$ for each hypothesis. According the bootstrapping parameters and Student T-test, all but one of the hypotheses are significant for at $0.05 ; \mathrm{H} 2$ (frequency) is not significant and therefore we cannot accept the hypothesis as true. Again, the predictive capability of the model is satisfactory in all but one case, because all $\mathrm{R}^{2}$ are greater than 0.10 except for the Frequency latent variable (Falk and Miller 1992). The cluster nodes IT and IG are not held to the same $R^{2}$ criteria since they are composite measures of the latent variables that determine the cluster (see Figure 3).

Hypothesis one asserts that the greater the use of information technology push/pull systems and storage measures, the more rapid speed of decision making associated with SID. The path loadings for both Distribution and Storage are positive and significant ( 0.585 and 0.487 respectively) to the IT cluster. Furthermore, the relationship between the $I T$ cluster and the model is significant and positive (0.152) and therefore supports the hypothesis.

Hypothesis two states that the greater the frequency of an organization's environmental scanning processes, the greater the speed in decision making associated with SID. For this model, the $\mathrm{R}^{2}$ is well below the 10 percent threshold and the bootstrap value is well below the 1.96 threshold; therefore, hypothesis two is rejected.

Hypothesis three states that the presence of a formal intelligence group will improve speed of decision making associated with the SID process. In this case, both presence of various formal structures and formal codification of those structures and processes have a positive and significant impact on the overall model (0.734 and 0.805 respectively). Furthermore, Presence accounts for 53 percent of the variance of the IG structure and Formal accounts for 65 percent. The $R^{2}$ values of the two latent variables in the IG cluster suggest that the survey has accounted for most of the variance in the dedicated group. The loading of the IG structure is both positive and significant (0.25); therefore, hypothesis three is accepted.

Finally, hypothesis four suggests that who sponsors the program increases the speed associated with decision making with respect to SID. The $R^{2}$ value is greater than the 10 percent threshold (19.8) and the path loading is both positive and significant (0.445); therefore, hypothesis four is accepted.

\section{Managerial Implications}

There are some firm level generalizations that may be derived from the nodes and clusters as illustrated in Figure 3. First, and this appeared counterintuitive to the research team, is that frequency of use does not matter with respect to speed of decision making within the SID process. Even though the literature supports the use of more information rather than less when making decisions in turbulent environments, our findings do not support these conclusions. One possible suggestion for this has to do with the quality of the information being gathered and the processes in place to deliver 
and receive information. It may be the case that the speed associated with decision making is not dependent upon the amount of contact associated between the decision maker and the $\mathrm{Cl}(\mathrm{Cl})$ unit but rather on the content and quality of the analysis and material provided.

Second, it matters who initiates and sponsors the $\mathrm{Cl}$ program. It appears that the higher in the organizational hierarchy the sponsor of the program resides, the more success that the program will experience. The level of sponsorship may be reflected in the reputation of the $\mathrm{Cl}$ group and, as such, reduces the degree of discussion required to convince decision makers of the validity of assumptions made by the group.

Finally, providing the necessary resources to both the information technology component of the $\mathrm{Cl}$ unit and formally documenting the group significantly impacts the SID performance as measured by speed in decision making. Formality provides a degree of status. This could speed issue diagnosis since it is capable of reducing the impact of political interests. Formality also serves to ensure the development of proper analysis tools. These tools are necessary to speed information processing. The implications for this are monetary as well as material since tools of this nature require constant upgrades and maintenance. This requires the organization to dedicate funding for the $\mathrm{Cl}$ group's continuous process and infrastructure improvements.

\section{Conclusions}

This study has a number of important implications to researchers and managers alike. We began this study with the intent to include an important component in the strategic issues diagnosis; namely, the inclusion of speed as a factor in the process. When the initial models for SIM systems and SID were developed in the 1990's, many industries were operating in more stable environments than today. The results of the last two decades have increased the amount of unpredictability and change than almost all industries are characterized by. The forces of globalization and increased technological change have had tremendous impacts on the planning horizons of organizations. This has intensified the need for an analysis of enhanced speed as a factor associated with strategic issue diagnosis. Our research included speed within the traditional SID framework, but focused on the structural impact of an organization's $\mathrm{Cl}$ activities on the speed of decision making within the strategic issues diagnosis framework. Few scholars have combined these two constructs previously. We suggest that many opportunities exist to explore further relationships between $\mathrm{Cl}$ and SID. This study has shown that speed matters and draws attention to the importance of $\mathrm{Cl}$ experts and effective use of their tools. Ultimately competitive advantage will rest with how quickly strategic issues can be resolved and responses can be launched.

There are some limitations to this study. First, a methodological limitation exists due to the small sample size (52 respondents) and to the difficulty of obtaining data. For this reason, we used the PLS optimization method, more oriented to the prediction than on the indicators stability (Barclay et al. 1995; Chin 1998). However, the only way to determine significance with PLS is through the bootstrapping technique. When 
bootstrapping is used, small samples such as ours tend to produce greater levels of variability in results (Hesterberg, Moore, Monaghan, Clipson, \& Epstein, 2005; Sosik et al., 2009). Therefore, we must take care in the interpretation of the significance and magnitude of the results. Second, the research only involved firms based in the Pittsburgh region. Although the study is limited geographically which precludes our ability to generalize beyond this area, we think that the dynamics of the region are indicative of environmental turbulence in general and therefore speaks to the issue of speed in action. Nonetheless, future research should extend the study model and validate the results within other geographic regions and industries. This study identified a set of relationships between $\mathrm{Cl}$ functions and speed of strategic issue diagnosis. Even though some managerial implications were identified and discussed, significant room remains to improve both the theoretical and practical aspects associated with this area of study.

\section{References}

Ansoff, I. H. (1980). Strategic issue management. Strategic Management Journal, 1(2), 131-148.

Ansoff, I. H. (1991). Strategic management in historical perspective. International Review of Strategic Management, 2, 449-461.

Benjamin, R. L., \& Levinson, E. (1993). A framework for managing IT-enabled change. Sloan Management Review, 34(4), 22-33.

Branzei, O., Ursacki-Bryant, T. J., Vertinsky, I., \& Zhang, W. (2004). The formation of green strategies in Chinese firms: matching corporate environmental responses and individual principles. Strategic Management Journal, 25(11), 1075-1095.

Brown, S. L., \& Eisenhardt, K. M. (1998). Competing on the edge: Strategy as structured chaos. Boston, MA: Harvard Business School Press.

Brown J. R., \& Lusch, R. F. (1992). Using key informants in marketing channels research: a critique and some preliminary guidelines. Advances in Distribution Channel Research, 1, 45-79.

Camillus, J. C., \& Datta, D. K. (1991). Managing strategic issues in a turbulent environment. Long Range Planning, 2, 67-74.

Chen, M. (1995). A model-driven approach to accessing managerial information: the development of a repository-based executive information system. Journal of Management Information Systems, 11(4), 33-63.

Child, J. (1972). Organization structure, environment, and performance: The role of strategic choice. Sociology, 6, 2-22.

Chin, W. W. (1998) The partial least squares approach to structural equation modeling. In: Marcoulides, G. A, (Ed.). Modern Methods for Business Research (pp. 295358). Mahwah, NJ: Lawrence Erlbaum.

Chin, W. W., \& Frye, T. (2003). PLS-graph version 3. University of Houston.

Daft, R. L., \& Weick, K. E. (1989). Toward a model of organizations as interpretation systems, Academy of Management Review, 9(3), 248-295.

D'aveni, R. (1995). Coping with hypercompetition: utilizing the new 7S's framework. Academy of Management Executive, 9(1), 45-60. 
Dillman, D. A. (2000). Mail and Internet Surveys: The Tailored Design Method. Wiley: New York.

Dutton, J. E., Fahey, L., \& Narayanan, U. K. (1983). Toward understanding strategic issue diagnosis. Strategic Management Journal, 4, 307-323.

Dutton, J. E., \& Ottensmeyer, E. (1987). Strategic issue management systems: Forms, functions and contexts. Academy of Management Review, 12, 355-365.

Dutton, J. E., Walton, E. J., \& Abrahamson, E. (1989). Important dimensions of strategic issues: separating the wheat from the chaff. Journal of Management Studies, 24(4), 379-396.

Dutton, J. E. (1993). Interpretations on automatic: a different view of strategic issue diagnosis. Journal of Management Studies, 30(3), 220-238.

Eisenhardt, K. M. (1989). Making fast strategic decisions in high-velocity environments. Academy of Management Journal, 32(3), 543-576

Falk, R. F., \& Miller, N. (1992). A Primer for Soft Modeling. The University of Akron Press.

Galbraith, J. (1973). Designing complex organizations. Reading, MA: Addison-Wesley.

Ginsberg, A., \& Venkatraman, N. (1992). Investing in new information technology: the role of competitive posture and issue diagnosis. Strategic Management Journal, 13(S1, Summer), 37-53.

Gudergan, S. P., Ringle, C. M., Wende, S., \& Will, A. (2008). Confirmatory tetrad analysis in PLS path modeling. Journal of Business Research, 61, 1238-1249.

Gulick, L. (1987). Time and public administration. Public Administration Review, 47, 115-119.

Hambrick, D., Geletkanycz, M., \& Fredrickson, J. (1993). Top Executive Commitment to the Status quo. Some tests of its determinants. Strategic Management Journal 14, 401-418.

Hawes, J. M., \& Crittenden, W. F. (1984). A taxonomy of competitive retailing strategies. Strategic Management Journal, 5(3), 275-287.

Heath, R. L. (2002). Issue management: its past, present and future. Journal of Public Affairs, 2(4), 209-214.

Heinrichs, J. H., \& Lim, J. (2008). Impact of marketing model application and competitive intelligence utilization on strategic response capability. Journal of Strategic Marketing, 16(2), 91-110.

Hesterberg, T., Moore, D. S., Monaghan, S., Clipson, A., \& Epstein, R. (2005). Bootstrap methods and permutation tests (2nd ed.). New York: Freeman.

Heugens, A. R. (2002). Strategic issues management: implications for corporate performance. Business and Society, 41(4), 456-468.

Holt, K. (2006). Strategic issues diagnosis identifies risks, opportunities. Hotel \& Motel Management, 221(5), 23-24.

Huber, G. P. (1991). Organizational learning: The contributing processes and the literatures. Organization Science, 2, 88-115.

Johnson, H. R., \& Carrico, S. R. (1988). Developing capabilities to use information strategically. MIS Quarterly, 12(1), 37-48.

Julian, S. D., \& Ofori-Dankwa, J. C. (2008). Toward an Integrative Cartography of two strategic issue diagnosis frameworks. Strategic Management Journal, 29, 93114. 
Kenny, D. (1979). Correlations and Causation. Wiley-Interscience, New York. King, W. R. (1982). Using strategic issue analysis. Long Range Planning, 15, 45-49.

Lambert, L. S. (2000)....And not a drop to drink: An integrated model of ethics and strategic issue diagnosis. Business Strategy and the Environment, 9, 318-327.

Lewin, A. Y., \& Stephens, C. A. (1994). CEO attributes as determinants of organizational design: an integrated model, Organization Studies, 15(2), 183212.

Lieberman, M. B., \& Montgomery, D. B. (1998). First Mover (dis)advantages: retrospect and link with the resource based view. Strategic Management Journal, 19(12), 1111-1116.

Mangin, J. L., Valenciano, J. P., \& Koplyay, T. M. (2009). Modeling distribution channel dynamics of North American care in the Spanish automobile industry. International Advances in Economic Research, 15, 186-206.

Maltz, E., \& Kohli, A. K. (1996). Market Intelligence dissemination across functional boundaries. Journal of Marketing Research, 33(1), 47-61.

March, J. G., \& Simon, H. A. (1958). Organizations. New York: Wiley.

Meyer, A. D., \& Goes, J. B. (1988). Organizational assimilation of innovations: a multinational contextual analysis. Academy of Management Journal, 31(4), 897923.

Meyer, A. D., Goes, J. B., \& Brooks, G. R. (1993). Environmental jolts and industry revolutions: organizational responses to discontinuous change. Strategic Management Journal, 11(4), 93-110.

Mintzberg, H., Raisinghani, D., \& Theoret, A. (1976). The structure of unstructured decision processes. Administrative Science Quarterly, 21, 246-275.

Pitt, M. (2005). A dynamic model of strategic change in growth-oriented firms. Strategic Change, 14(6), 307-326.

Rajogopalan, N., Rasheed, A. M. A., \& Datta, D. K. (1993). Strategic Decision Processes: critical review and future directions. Journal of Management, 19(2), 349-383.

Reich, B. H., \& Benbasai, I. (1996). Measuring the Linkage between business and information technology objectives, MIS Quarterly, 20(1), 55-81.

Simon, H. A. (1960). The new Science of Management Decision. New York: Harper \& Row.

Simon, H. A. (1973). Applying information technology to organizational design. Public Administration Review, 33, 268-273.

Smith, K., \& Grimm, C. (1991). A communication-information model of competitive response timing. Journal of Management, 17, 5-23.

Sosik, J. J., Kahai, S. S., \& Piovoso, M. J. (2009). Silver bullet or voodoo statistics? A primer for using the partial least squares data analytic technique in group and organization research. Group \& Organization Management, 34(1), 5-36.

Tee, S. W., Bowen, P. L., Doyle, P., \& Rohde, F. H. (2007). Factors influencing organizations to improve data quality in their information systems. Accounting and Finance, 47, 335-355.

Thomas, P. S. (1980). Environmental scanning - The state of the art. Business Horizons, 17, 27-38. 